\title{
O que a Pandemia nos Pode Ensinar acerca da Avaliação Externa das Aprendizagens?
}

\section{What Can the Pandemic Outbreak Teach us about External Learning Assessment?}

\author{
Nuno Miranda* \\ Sónia Pereira \\ Universidade de Évora, Portugal
}

\begin{abstract}
A tempos de pandemia obrigaram o sistema educativo português a mudar e assumir prioridades. Em particular, debateu-se o lugar das avaliações externas das aprendizagens (AEA). Esta investigação pretende conhecer quais são as narrativas de contexto (a educação em tempos de pandemia) dos agentes (representantes do estado, famílias, diretores, professores, alunos e academia), que posições tomam acerca da AEA e com que justificação. Dada a natureza das perguntas, inscreve-se no paradigma interpretativo, com abordagem mista e na modalidade de estudo de caso, com recurso à análise documental de registos públicos. Os resultados são discutidos pelo contraste com outros dados científicos e com as decisões políticas adotadas devido ao surto de Covid19. Sugerem que a AEA para acesso ao ensino superior ganha o estatuto de finalidade da aprendizagem e que isso contribui para dissonâncias importantes: os agentes assumem narrativas de promoção da equidade social e adotam medidas com potencial para a inquinar. Consideramos, a concluir, que outras decisões poderiam ter sido tomadas (apresentamos exemplos) e que o processo de mudança teria beneficiado de um período de reflexão orientado para a coerência entre necessidades, recursos e conhecimento.
\end{abstract}

Palavras chave: Avaliação externa; Pandemia; Política educativa; Evaliação do estudante; Justiça social.

The Covid outbreak forced the portuguese education system to change and to assume priorities. In particular, the importance of learning external assessment (LEA) was put in to focus. This research intends to know what the narratives of context of the agents are (the education in times of pandemic), what positions they take about the LEA and with what justification. Given the nature of the questions, is inscribed in the interpretive paradigm, with a mixed approach and in the case study modality, using document analysis of public records. The results are discussed in contrast with other scientific data and with the political decisions adopted due to the Covid 19 outbreak. They suggest that the LEA for access to higher education gains the status of learning purpose and that this contributes to important dissonances: the agents assume narratives to promote social equity and adopt measures with the potential to minimize it. In conclusion, we consider that other decisions could have been taken (we present examples) and that the change process would have benefited from a period of reflection oriented towards the coherence between needs, resources and knowledge.

Keywords: External assessment; Pandemic; Educational policy; Student assessment; Social justice.

*Contacto: nunosilva@aemn.pt

ISSN: 2254-3139

www.rinace.net/riejs/

revistas.uam.es/riejs
Recibido: $\quad 15$ de junio 2020

$1^{\text {a }}$ Evaluación: 13 de agosto 2020

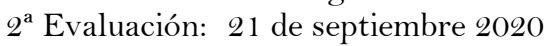

Aceptado: 3 de octubre 2020 


\section{Introdução}

A avaliação externa das aprendizagens (AEA) tem tido um lugar relevante no sistema educativo português. Por um lado, há raízes históricas que reverberam nas comunidades e que colocam os "exames" como garantia de qualidade das aprendizagens e, até, de emancipação social. Por outro, sabemos que tem impactos significativos dentro das salas de aula, tornando-se um foco da atenção dos professores, dos alunos (Fernandes, 2019; Madaus, Russell e Higgins, 2009) e das escolas, já que os resultados das AEA são mobilizados para as avaliar e comparar.

Neste contexto, vários autores têm vindo a salientar a necessidade de harmonizar os processos de avaliação interna e externa (Black e Wiliam, 2010; Fernandes, 2014, 2019), para que se dirijam à essência do processo educativo, a aprendizagem dos alunos e assegurem a equidade social; e essa concertação pode ser beneficiada se compreendermos as representações que os agentes fazem das funções e objetivos dos vários tipos de AEA.

Contudo, são raros os momentos que nos permitem aceder ao que está enraízado no sistema educativo. Sabemos, aliás, que algumas reformas educativas falham porque, apesar das mensagens, têm pouco poder para alterar crenças profundas (Fullan, 2009).

Os tempos de pandemia em que vivemos podem, precisamente, deixar emergir o que está oculto e contribuir para que compreendamos melhor os fatores que estão a influenciar a ação, já que qualquer expectativa de vivência social integra, necessariamente, a aprendizagem. Assim, debatem-se, ideias acerca das finalidades da educação e da importância relativa dos seus componentes e tomam-se decisões que ponderaram a relevância das AEA.

Que importância lhes é dada nas narrativas de contexto (a educação em tempos de pandemia)? Que formas de AEA são consideradas indispensáveis e porquê? Que argumentos justificam a tomada de decisão? Qual o diálogo possível entre as decisões, as evidências científicas e as representações dos agentes? Estas questões tornam-se tão mais relevantes porque a pandemia traduz um momento em que não há modelos anteriores para guiar a ação, o que significa que a reflexão e os valores ganham primazia - portanto que a ética está profundamente envolvida e deve ser alimentada (Cilliers, 2000; Shapiro e Stefkovich, 2005; Silva, 2019).

É precisamente neste espaço ético que nos propomos atuar. Para isso, desenvolvemos uma pesquisa para acedermos às narrativas dos principais agentes de decisão e influência (membros do governo, representantes de professores, famílias, direções escolares, alunos e academia), ocorridas entre 8 de março e 19 de abril (período em que foram previstas e tomadas decisões sobre a reorganização da educação) em função das questões que apresentamos anteriormente.

Este artigo estrutura-se em quatro partes. A primeira é destinada a identificar os tipos de AEA em Portugal e os seus objetivos e impactos. Na segunda, descreve-se o quadro metodológico que presidiu à investigação. A terceira apresenta os resultados das narrativas de contexto sobre a educação em tempos de pandemia e das narrativas específicas acerca da AEA. Na quarta parte discutimos os resultados, colocando-os em perspetiva face aos tipos e funções da AEA, a outras investigações e às decisões tomadas no período estudado. Terminamos com conclusões orientadas para a tomada de decisão. 


\section{Avaliação externa das aprendizagens dos alunos: Objetivos, processos e impactos}

As provas de AEA parecem ter a capacidade de incitar a dedicação focada dos alunos e professores, provavelmente porque estão ligadas ao futuro profissional dos primeiros e à responsabilização dos segundos. Por isso, é tão relevante compreendermos o que os agentes pensam e as crenças por que agem. Como conceito, a AEA deve ser entendida por

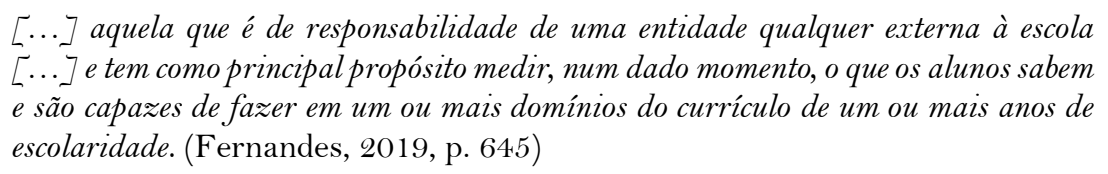

Tem vindo a ser tomada como instrumento capaz de cumprir, simultaneamente, múltiplos objetivos (Best et al., 2013), embora subordinados ao racional abrangente de contribuir para que os alunos aprendam mais e melhor.

As finalidades que têm justificado o recurso à AEA são o julgamento das aprendizagens para a progressão/certificação/ordenação dos alunos; a pilotagem e avaliação das escolas e do sistema de ensino; e o apoio ao processo de ensino (Eurydice, 2009). Em Portugal, as narrativas dos agentes políticos colocam as AEA como motores de mudança educativa, capazes de justificar a autonomia das escolas, suportar os projetos educativos e regular o sistema educativo (Carvalho, Costa e Sant'Ovaia, 2020).

A finalidade de certificação, progressão e ordenação dos alunos é satisfeita com exames padronizados que permitem um balanço sumário das aprendizagens. Os resultados dessas provas, são integrados no sistema de classificação, numa relação que tem sido considerada moderada (moderate stakes) (Fernandes, 2019).

Ocorrem nas disciplinas de Língua Portuguesa e Matemática no termo do terceiro ciclo do Ensino Básico (Provas Finais do $9^{\circ}$ ano), com uma ponderação de 30\% relativamente à classificação final; e no ano terminal das disciplinas específicas e da disciplina de Português dos Cursos Científico-Humanísticos do ensino secundário (cuja orientação é a de preparar os alunos para o ensino superior), com uma ponderação igualmente de $30 \%$ da classificação das respetivas disciplinas (Exames Finais do $11^{\circ}$ e $12^{\circ}$ anos).

Inclui uma forma particular que funciona como um gatekeeper, orientado para a seleção dos alunos no acesso ao ensino superior. Aqui, os Exames Nacionais ganham valor, já que têm uma ponderação de entre $35 \%$ a $50 \%$ da classificação no concurso de acesso. Esta função é destinada a moderar a relação entre a avaliação interna e externa e a prevenir diferenças de classificação devido a critérios de avaliação diferenciados aplicados pelas escolas (ver, por exemplo, Direção-Geral de Educação/Júri Nacional de Exames, 2019 e o Parecer n. ${ }^{\circ}$ 2/2016 do Conselho Nacional da Educação). Esta parece ser uma das vantagens da AEA, já que aporta rigor na medição dos conhecimentos, a um nível que as avaliações internas, individualmente, parecem não ser capazes (Fernandes, 2019). Alguns autores consideram que outra vantagem é a clarificação sobre o que é verdadeiramente importante aprender e ensinar, o que tem levado ao ganho de consistência intra-escola e inter-escola (Crocker, 2004; Jones, 2007).

Portanto, este tipo de AEA tem sido legitimada pelos argumentos de que através delas os alunos aprendem mais e que o processo educativo é mais justo e confiável. Contudo, a ciência tem evidenciado os limites destas justificações. 
Por um lado, os impactos deste tipo de AEA são mais negativos do que positivos, uma vez que promove o estreitamento do currículo e a desvalorização social das aprendizagens de disciplinas que não são alvo de AEA (Au, 2008; Madaus, Russell e Higgins, 2009).

Aliás, o próprio potencial de avaliação das provas de AEA parece ser limitado face à organização atual do sistema de ensino português. Nele, a aprendizagem opera através do Perfil do Aluno à Saída da Escolaridade Obrigatória (Despacho n. ${ }^{\circ}$ 6478/2017, de 26 de julho), assente no desenvolvimento de valores (por exemplo, liberdade, cidadania e participação) e competências (por exemplo, domínio do corpo e pensamento crítico e criativo), em alinhamento com a ideia de que o imprevisível futuro da humanidade aconselha a que as crianças e jovens desenvolvam competências e valores transversais e adaptáveis (Conselho da União Europeia, 2018; Morin, 1999). Em função deste conjunto de aprendizagens, o Perfil oferece possibilidades de ação, para que o percurso educativo tenha a diversidade de que as crianças e jovens necessitam; tem uma lógica transdisciplinar que bebe de metodologias variadas (Sousa-Pereira e Leite, 2019) e instrumentos de avaliação essencialmente formativos.

Naturalmente, a avaliação deste tipo de aprendizagens está dependente de interações e de situações práticas e continuas debilmente aferíveis a partir de, apenas, uma prova escrita e, pelo contrário, integra o quotidiano da relação que os alunos estabelecem com os colegas e os professores.

Por outro lado, também sabemos que a AEA tem limitações processuais, individuais e sociais:

- Ao nível do processo, o rigor não é perfeito. Por exemplo, na primeira fase de exames nacionais de $2018,75 \%$ das provas reapreciadas viram a classificação subir $^{1}$

- Quanto ao seu impacto nos individuos, está ligada à redução dos níveis de motivação intríseca (Harlen, 2003) e ao aumento de afeções de saúde mental (Cho e Chan, 2020);

- Em termos sociais, parece não ser capaz de garantir a justiça ou a equidade, já que o seu uso para acesso ao ensino superior tem efeitos negativos nos alunos que não têm bons desempenhos (Harlen, 2003), com aqueles provenientes de ambientes desfavorecidos a alcançarem resultados inferiores (Salmi e Bassett, 2014) e os alunos com mais poder económico a poderem recorrer a apoios extraescolares (Bray, 2007; Pinto, Costa e Silva, 2014), o que traduz a redução da equidade social (Baker e Johnston, 2010; Bray, 2007; Salmi e Bassett, 2014).

A finalidade de acompanhamento e avaliação das escolas e do sistema educativo está orientada para a comparação de desempenhos. Por um lado, o sistema educativo e as escolas são reguladas e responsabilizadas, através do relato dos resultados aos agentes relevantes. Por outro, os resultados também ser usadas para balanço de medidas específicas de política educativa.

Sabemos que nos anos mais recentes, muitas políticas foram tomadas a partir dos resultados dos alunos em provas de exame ou em provas de comparação internacional (Afonso e Costa, 2014; Grek, 2009), influenciando o investimento público e a

\footnotetext{
${ }^{1}$ Dados extraídos do relatório anual acerca das AEA.
} 
reorganização dos sistemas de ensino e traduzindo uma alteração do foco da organização política, dos processos para os resultados (Lingard, Martino e Rezai-Rashti, 2013; Maroy e Voisin, 2013; Ozga e Grek, 2012). Em certa medida, as AEA têm contribuído para a homogeneização transnacional em torno da importância do raciocínio do conhecimento científico e da matemática na aprendizagem (Smith, 2014) em deterimento de outras áreas, o que, no contexto nacional, é traduzido por um historial de valorização das disciplinas de matemática (até 2015, estavam implementadas AEA com impacto na progressão dos alunos nos $4^{\circ}, 6^{\circ}$ e $9^{\circ}$ anos de escolaridade. Remanescem no $9^{\circ}$ ano).

Esta finalidade não recorre a um instrumento próprio, recolhendo, inputs de todos eles (provas de aferição, provas de avaliação e exames), para os conjugar com outras formas de regulação. Por exemplo, a avaliação externa das escolas tem uma componente dedicada aos resultados dos alunos nas AEA (Inspeção-Geral da Educação e da Ciência, 2020), o que permite alguma comparabilidade entre escolas e entre os sistemas público e privado, num processo que tem contribuído para a uniformização das escolas (Afonso, 2009; Conselho Nacional de Educação, 2015).

A finalidade de apoiar o processo de ensino junta as vertentes informativa e formativa, já que visa esclarecer as necessidades específicas de aprendizagem dos alunos e identificar necessidades de reformulação didático-pedagógica de escolas e, eventualmente, aponta para o acompanhamento individual e o ensino adaptado (Eurydice, 2009; Fernandes, 2014; Johnson, 1992).

Em Portugal estão em campo as provas de aferição no $2^{\circ}$ ano $\left(1^{\circ}\right.$ ciclo $), 5^{\circ}$ ano ( $2^{\circ}$ ciclo $)$ e $8^{\circ}$ ano $\left(3^{\circ}\right.$ ciclo $)$ de escolaridade. Esses anos foram selecionados porque correspondem a um momento do ciclo de ensino em que é possível implementar estratégias de remedeio ou reconfigurar o processo de aprendizagem² ${ }^{2}$

As provas dão origem a relatórios individuais e a relatórios globais, pelo que fornecem informação específica aos alunos, famílias, professores, escolas, comunidades e sistema. Os resultados deste tipo de AEA não produzem quaisquer efeitos diretos na progressão e certificação dos alunos.

\section{Metodo}

Assumimos o objetivo de descrever e compreender as representações dos agentes educativos acerca da AEA no período de pandemia e colocá-las em diálogo com outros dados produzidos pelas Ciências da Educação, no racional de que é nos períodos de imprevisibilidade que a ciência deve assessorar o debate público e a decisão política. Estabelecemos as seguintes perguntas de investigação:

No período de 8 de março a 19 de abril, em que o sistema educativo esteve sujeito a alterações em virtude da crise pandémica:

\footnotetext{
${ }^{2} \mathrm{O}$ sistema educativo português organiza-se por ciclos de ensino obrigatórios, entendidos como períodos de tempo em que os alunos devem desenvolver determinadas competências e valores. $\mathrm{O}$ $1^{\circ}$ ciclo comporta quatro anos; o $2^{\circ}$ ciclo, os $5^{\circ}$ e o $6^{\circ}$ anos; o terceiro ciclo, os $7^{\circ}, 8^{\circ}$ e $9^{\circ}$ anos e o ensino secundário os $10^{\circ}, 11^{\circ}$ e $12^{\circ}$ anos de escolaridade.
} 
- Quais são as narrativas de contexto que os agentes (governo, representantes de direções escolares, representantes de professores, representantes de encarregados de educação, membros da academia e alunos) adotam?

- Qual a posição dos agentes acerca da AEA?

- Que argumentos são utilizados para justificar as posições adotadas?

\subsection{Paradigma, abordagem e modalidade}

Dada a natureza das perguntas, a investigação:

- inscreve-se no paradigma interpretativo, porque se destina a compreender a realidade na perspetiva de quem a vive (Coutinho, 2011), pela interpretação de representações;

- assume uma abordagem mista, já que mobiliza os discursos dos agentes para compreender um fenómeno (Merriam e Tisdell, 2016; Stake, 2009) e a frequência das codificações, o que, em conjunto, favorece a captura e desocultação das perceções que estão na base da ação dos atores (Creswell, 2012; Merriam e Tisdell, 2016);

- insere-se na modalidade de estudo de caso, porque convoca um fenómeno circunscrito (Merriam e Tisdell, 2016), caraterizado pela interação de agentes múltiplos, cujas representações permitem a triangulação enriquecida dos resultados.

\subsection{Procedimentos e recolha de dados}

A recolha de dados ocorreu por análise documental. Por um lado, os documentos são registos fidedignos e acessíveis acerca das crenças e valores dos agentes; por outro, o seu caráter não reativo liberta-os, em certa medida, da interpretação dos investigadores (Hatch, 2002; Merriam e Tisdell, 2016); e, também, são fontes relevantes para as investigações que, como esta, exigem por dados e discussões imediatas.

Contudo, é de salientar que esse mesmo caráter estático dos documentos significa que não podem ser olhados fora dos objetivos do agente que os emite. Por exemplo, as decisões do estado português tendem a resultar em registos explicativos das deliberações, enquanto entidades representativas podem adotar posições críticas.

Neste caso, aceitou-se fontes primárias e secundárias - em busca da saturação dos resultados. Recorreu-se a registos de meios de comunicação social e a documentos disponibilizados nos sítios das entidades, em função dos seguintes critérios: a facilidade de acesso aos conteúdos, o número de subscritores da versão online do jornal, o número de ouvintes dos programas de rádio e a orientação para o serviço público. Aceitou-se o critério "bola de neve" para mobilizar dados de agentes menos presentes, como o caso dos alunos (em que se usou dados de uma petição pública) e da Comissão Nacional de Acesso ao Ensino Superior.

Ponderados estes critérios, foram recolhidos os documentos/registos entre os dias 8 de março (em que surgiram as primeiras narrativas que relacionavam a pandemia e a educação em Portugal) e o dia 19 de abril (altura em que o foco das narrativas deixou de ser a adoção de medidas para o presente ano letivo) dos seguintes locais:

- Secção educação do jornal “O Público” (61 notícias); 
- Revista "Fórum Estudante" - uma entrevista;

- Programas radiofónicos "Fórum TSF" (Rádio TSF) e "Antena Aberta" (Rádio Antena 1) relacionados com a temática (5 registos);

- Sítios da Direção-Geral da Educação, das entidades consultivas em matéria de educação (Conselho Nacional de Educação e Conselho das Escolas), das entidades representativas dos professores (Federação Nacional dos Professores e Frente Nacional de Educação), diretores (Associação Nacional de Dirigentes Escolares e Associação Nacional de Diretores de Agrupamentos e Escolas), encarregados de educação (Confederação Nacional de Associações de Pais e Confederação Nacional Independente de Pais e Encarregados de Educação) e de centros de investigação em educação (Universidades de Aveiro, Lisboa, Minho e Évora) (18 registos);

- Em particular o estado português foi considerado nas pessoas do Ministro da Educação, Secretário de Estado Adjunto e da Educação e Presidente da Comissão de Acesso ao Ensino Superior, uma vez que se buscava por discursos dirigidos apenas para a relação entre a pandemia e a educação.

Em resultado, foram analisados 143 momentos (alguns registos permitiram mobilizar vários casos), com a seguinte frequência de codificações por agente (Tabela1):

Tabela 1. Frequência das narrativas consideradas por agente

\begin{tabular}{lc}
\hline \multicolumn{1}{c}{ AGENTE } & FREQUÊNCIA DAS CODIFICAÇÕES \\
\hline Estado & $22,3 \%$ \\
Ciência & $12,8 \%$ \\
Diretores & $24 \%$ \\
Professores & $26,6 \%$ \\
Encarregados de educação & $8,9 \%$ \\
Órgãos consultivos & $4,0 \%$ \\
Alunos & $1,4 \%$ \\
\hline Fon
\end{tabular}

Fonte: Elaboração própria.

\subsection{Tratamento dos dados}

Os dados, organizados no programa QDA Miner, foram tratados por análise das frequências de codificação e por análise de conteúdo, técnica com mais pertinência quando os dados têm caráter qualitativo, já que permite extraír-lhes o sentido (Creswell, 2012; Peräkylä, 2005). A análise de cada investigador foi independente, para efeitos de triangulação e as divergências foram harmonizadas por consenso.

Para a análise de conteúdo, fez-se a transcrição dos registos áudio e vídeo. Depois, procedemos a uma análise exploratória preliminar, com os objetivos de ganhar uma visão geral dos dados e tomar decisões acerca da sua organização. Assim, selecionaram-se os dados que poderiam ser tratados a partir da teoria de referência (tipos de AEA), e aquela cuja análise requereria a exploração de categorias. Sobre estes, procedemos a nova análise exploratória, com o objetivo de identificar as categorias emergentes. Em resultado:

- Para os dados denominados "Narrativas de contexto", as categorias foram extraídas após a recolha de todos os dados, por um processo de classificação progressiva dos elementos. O título e a definição das categorias foram gerados com base nas declarações e palavras utilizadas pelos agentes (apesar de termos refinado as representações em títulos- resumo), através da redução e agregação 
das narrativas (Creswell, 2012), em que as categorias iniciais (A1 saúde, A2 mais importante que a educação, B1 apoio alimentar, B2 segurança das crianças e jovens, B3 apoio social, C1 conteúdos, C2 avaliação, C3 estratégias de ensino, C4 equipamentos, D1 acesso futuro ao ensino superior, D2 educação digital no próximo ano letivo, E1 equidade, E2 igualdade e E3 acesso à aprendizagem) deram origem a 5 categorias: (A) tema acima da educação, (B) papel social da escola, (C) aprendizagem, (D) educação do futuro e (E) equidade e igualdade (Tabela 2);

- Para os dados específicos acerca da AEA, recorrereu-se a análise de conteúdo de verificação (Creswell, 2012; Hatch, 2002; Merriam e Tisdell, 2016), uma vez que se mobilizam as estruturas teóricas acerca dos tipos, impactos e objetivos da avaliação externa das aprendizagens, conforme proposto pela Eurydice (2009) e de acordo com os critérios gerais apresentados na tabela 2 .

Tabela 2. Categorias e critérios de codificação

\begin{tabular}{|c|c|c|c|}
\hline $\begin{array}{l}\text { PERGUNTA DE } \\
\text { INVESTIGAÇÃo }\end{array}$ & Categorias & SUBCATEGORIAS & $\begin{array}{c}\text { CRITÉRIOS (DISCURSOS } \\
\text { SOBRE...) }\end{array}$ \\
\hline \multirow{5}{*}{$\begin{array}{l}\text { Narrativas de } \\
\text { contexto que os } \\
\text { agentes adotam? }\end{array}$} & \multirow{5}{*}{$\begin{array}{l}\text { Narrativas de } \\
\text { contexto }\end{array}$} & $\begin{array}{l}\text { Tema acima da } \\
\text { educação }\end{array}$ & $\begin{array}{l}\text { A educação como subsidiária } \\
\text { da saúde. }\end{array}$ \\
\hline & & Papel social da escola & $\begin{array}{l}\text { As funções sociais da escola } \\
\text { (alimentação, } \\
\text { complementaridade } \\
\text { económica, proteção, } \\
\text { inclusão). }\end{array}$ \\
\hline & & Aprendizagem & $\begin{array}{l}\text { Os fatores diretamente } \\
\text { relacionados com os processos } \\
\text { de ensino e de aprendizagem. }\end{array}$ \\
\hline & & A educação do futuro & $\begin{array}{l}\text { As alterações ao sistema de } \\
\text { ensino que a situação } \\
\text { pandémica sugere serem } \\
\text { necessárias. }\end{array}$ \\
\hline & & Equidade e igualdade & $\begin{array}{l}\text { A igualdade de acesso à } \\
\text { aprendizagem e a } \\
\text { diferenciação das atividades. }\end{array}$ \\
\hline $\begin{array}{l}\text { Posição acerca da } \\
\text { avaliação externa } \\
\text { das } \\
\text { aprendizagens? }\end{array}$ & \multirow{3}{*}{$\begin{array}{l}\text { Posição } \\
\text { Argumentos }\end{array}$} & $\begin{array}{l}\text { Certificação, } \\
\text { progressão e } \\
\text { ordenação } \\
\text { Pilotagem e avaliação }\end{array}$ & \multirow{2}{*}{$\begin{array}{l}\text { As funções, objetivos, efeitos } \\
\text { ou utilidade da tipologia de } \\
\text { AEA. }\end{array}$} \\
\hline \multirow{2}{*}{$\begin{array}{l}\text { Que argumentos } \\
\text { as justificam? }\end{array}$} & & $\begin{array}{l}\text { do sistema } \\
\text { Apoio à } \\
\text { aprendizagem. }\end{array}$ & \\
\hline & & Geral & $\begin{array}{l}\text { A AEA, sem que se dirijam } \\
\text { aos objetivos, funções, efeitos } \\
\text { ou usos específicos. }\end{array}$ \\
\hline
\end{tabular}

Fonte: Elaboração própria.

Um último parágrafo para reconhecer que o recurso à interpretação dos dados nunca está inteiramente livre de subjetividades. Sobretudo, a educação é um campo propício a ambivalências e a análise não é um momento mecânico. Por isso, clarificamos que o nosso percurso interpretativo está arraigado na teorização de que a educação tem uma ontologia complexa, ocasionadora de surpresas e incertezas, em que cada um dos seus agentes tem capacidade de interagir e modificar o próprio sistema e de co-evoluir com ele. Temos a expectativa de que esta clarificação - juntamente com a diversidade de fontes, 
investigadores e descrição detalhada do processo - seja entendida como um ponto de credibilidade e consistência da pesquisa.

\section{Resultados}

Começamos por caraterizar três fases que se diferenciam por decisões que alteraram o funcionamento do sistema educativo. Em seguida, apresentamos as narrativas de contexto, que estabelecem a visão geral da educação em tempo de pandemia e, depois, dirigimo-nos aos resultados específicos das narrativas sobre a AEA.

\subsection{Três fases de decisão e ação}

As decisões, inquietações e energias dos agentes são mobilizadas diferentemente em função de três fases (figura 1).

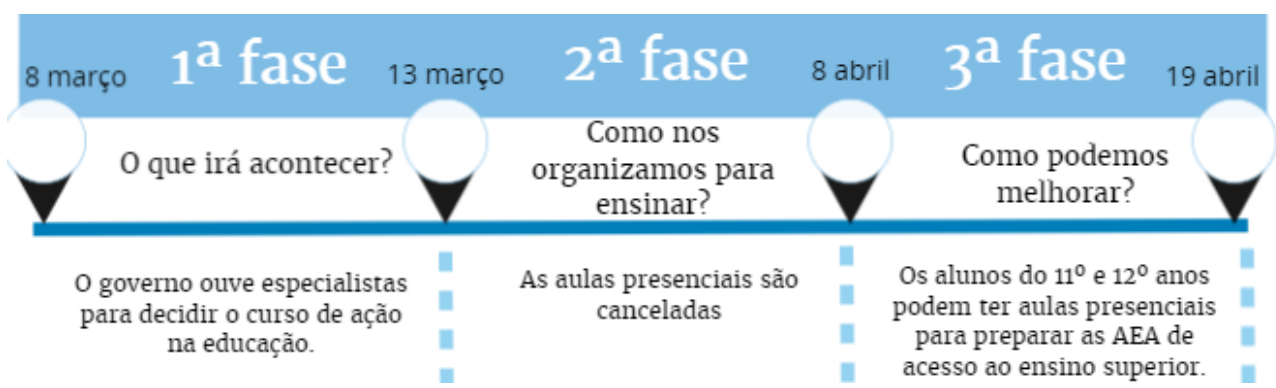

Figura 1. Fases de decisão sobre a educação em tempos de pandemia Fonte: Elaboração própria.

A primeira refere-se aos dias antes de 13 de março, em que se aguardava pelas recomendações do Conselho Nacional de Saúde Pública (CNSP) sobre a educação face à pandemia. A pergunta que carateriza este período é “O que irá acontecer?", com os agentes a anunciarem o respeito pelas decisões vindouras, em função do bem maior da saúde pública.

A segunda fase tem início no dia 13 de março, data em que o estado determinou o encerramento de todas as escolas (apesar da recomendação noutro sentido do CNSP) e a tramitação das atividades letivas para o ensino à distância. Nele, os agentes estão mobilizados em torno da adaptação à nova realidade (o recurso a formas diferentes de ensinar e aprender) e à antecipação das possibilidades de ação na fase seguinte. Foi balizado pelo anúncio de que o dia 9 de abril corresponderia a um balanço da situação

Assim, a terceira fase tem início no dia 9 de abril. O governo anuncia que as Provas de Aferição e as Provas Finais do $9^{\circ}$ ano são canceladas, que a certificação dos alunos recorreria, exclusivamente, à avaliação interna e que os Exames Nacionais do $11^{\circ}$ e $12^{\circ}$ anos seriam mantidos tendo em vista, unicamente, o acesso ao ensino superior. Por isso, apenas os alunos destes dois anos teriam de voltar a ter aulas presenciais (com início em data a anunciar), apenas nas disciplinas com exame nacional final e na situação de estarem garantidas as condições de segurança e somente no caso dos encarregados de educação não se oporem à frequência dos seus educandos (caso o façam, as faltas dos alunos são consideradas justificadas). É, também, anunciado um programa de ensino através da televisão pública -\#EstudoEmCasa-, destinado aos alunos do $1^{\circ}$ ao $9^{\circ}$ anos, como 
mecanismo complementar de aprendizagem, orientado para a promover a igualdade de acesso.

Neste período, as preocupações dos agentes estão centradas na consolidação e melhoria do ensino à distância.

\subsection{A educação em tempos de pandemia: As narrativas de contexto}

Neste subcapítulo, dirigimo-nos à primeira pergunta de investigação: Quais são as narrativas de contexto que os agentes adotam? Emerge uma narrativa transversal a todas as fases e agentes: as decisões, ações e atitudes devem estar subordinadas à saúde e segurança (representa 12,4\% das codificações):

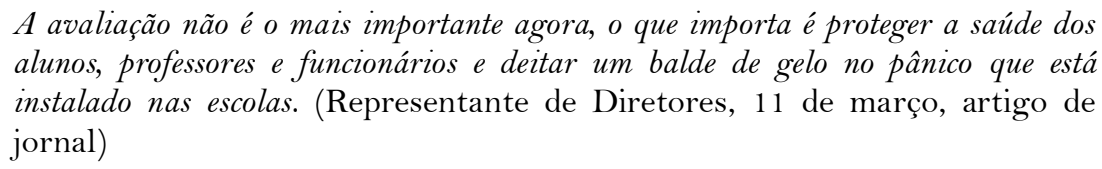

A partir deste valor ubíquo, o contexto é definido por três temas agregadores dos discursos: a aprendizagem, o papel social da escola e as modificações futuras que a pandemia sugere. Eles emergem, sobretudo, a partir da segunda fase e são atravessados por um subtema: equidade e igualdade (figura 2 ).

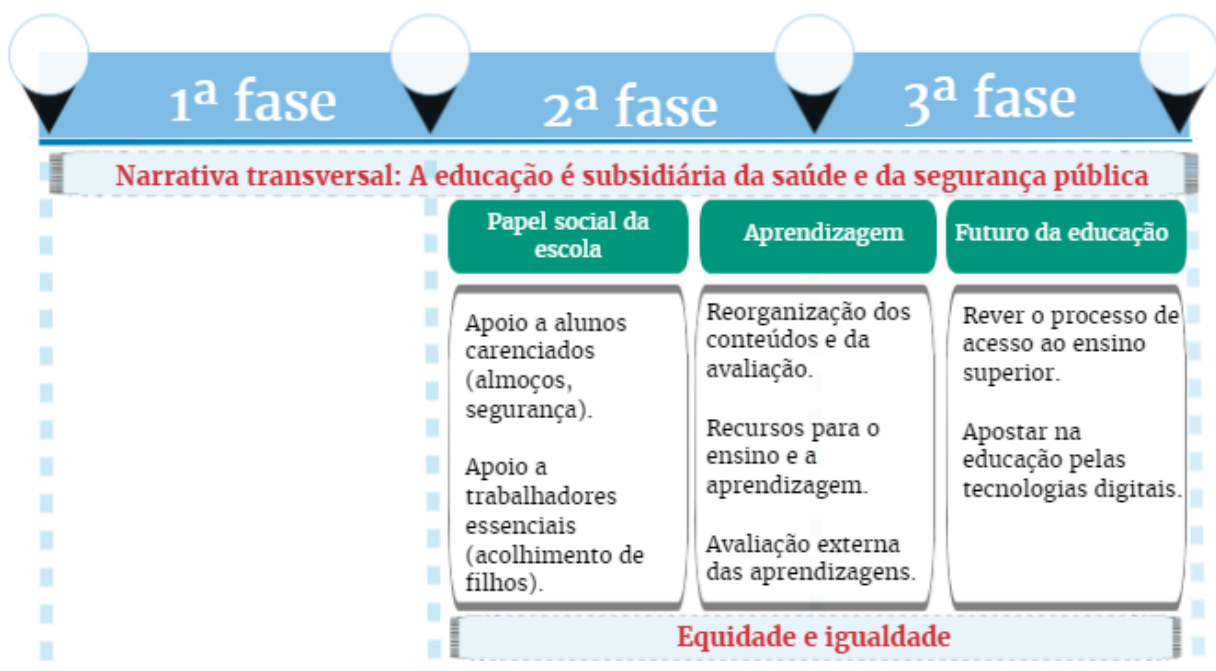

Figura 2. Narrativas de contexto

Fonte: Elaboração própria.

O tema "Papel social da escola" (3,5\%) revela a valorização de serviços (principalmente as refeições) a alunos com apoios sociais escolares, do acolhimento de filhos de trabalhadores das áreas da saúde e segurança, mas também do controle e proteção social que a frequência escolar oferece.
Antes de chegarmos às aprendizagens, nós sabemos que a escola tem uma função importante na proteção social, porque sabemos que há lares com violência, negligência, onde não há comida e as escolas são espaços onde é possivel identificar e resolver situações onde não há comida e angustia-me pensar que este elo de proteção não funciona tão bem à distância. Estamos a garantir que estes alunos não ficam sozinhos, na medida em que têm um contacto diário com vários professores, com professores que eram tutores. (Estado, 15 de abril, entrevista a programa radiofónico)

O tema "Aprendizagem" inclui o conjunto dos discursos que são dirigidos para os processos de ensino e aprendizagem e recebe a maioria das referências $(65,5 \%)$. Os dados 
apontam que os agentes estão sensíveis à avaliação dos alunos (Como reformular? Como ser justo?), à garantia da manutenção das aprendizagens e aos recursos e condições necessários para que elas ocorram (recursos pedagógicos e clarificação dos conteúdos a ensinar). É neste tema que se localizam as narrativas acerca da AEA, com 25,6\% do total de codificações.

Na generalidade, os discursos dos agentes são próximos. Reconhecem (a) a validade da avaliação interna, assente em instrumentos de continuidade, (b) a necessidade de rever, em cada escola, os critérios de avaliação a aplicar no $3^{\circ}$ período letivo e que (c) a progressão e certificação dos alunos devem recorrer apenas à avaliação interna; (d) que as duas primeiras semanas de ensino à distância deram origem a excessos de tarefas e não permitiram harmonizar parcerias pedagógicas entre famílias e docentes e que (e) as escolas estavam melhor preparadas depois de 8 de abril, porque (f) a interrupção letiva da Páscoa tinha proporcionado tempo de preparação. Defendem que (g) os impactos da situação de pandemia na aprendizagem dos alunos devem estar na origem de estratégias de remedeio a tomar a partir do próximo ano letivo. Por exemplo:

\begin{abstract}
Isto é um desafio para todos, os pais têm um desafio, [...] e eu faço o apelo, é preciso que eles ajudem de alguma forma os seus professores, com supervisão, sendo certo que percebemos que nos últimos 15 dias, os nossos alunos tiveram muitas tarefas pedagógicas. Com certeza que os nossos professores não enviarão tantas tarefas pedagógicas como aquelas que enviaram devido ao facto de ser uma primeira fase. Vamos corrigir isso. (Representante dos Diretores, 13 de abril, entrevista a programa radiofónico)

Naquilo que se puder atenuar a desigualdade, os professores saberão fazê-lo, pois essa também é uma responsabilidade que assumem. Porém, quando os alunos voltarem às escolas o governo terá de compreender que é preciso reforçar a contratação de docentes para garantir apoio pedagógico extraordinário a todos os alunos. (Representante dos professores, 27 de março, vídeo de entrevista televisiva)
\end{abstract}

E o tema "Futuro da educação" (4,8\% das codificações) traduz a emergência de dinâmicas orientadas para as modificações do sistema educativo que a pandemia aponta, a necessidade de pensar uma componente forte de educação pelas tecnologias digitais

E pensar a sério, mais do que nunca, num programa nacional de democratização das novas tecnologias, quer por via do acesso a equipamentos, quer por via da universalização da Internet. (Representante dos Encarregados de Educação, 9 de abril, artigo de jornal)

E a revisão do modelo de acesso ao ensino superior:

(...) olhe e é uma oportunidade de trazer para a agenda de trabalhos o modelo de acesso ao ensino superior, que nós, diretores, temos debatido e discordamos. Como sabe, está muito vocacionado e depende muito dos exames do ensino secundário. (Representante dos Diretores, 13 de abril, vídeo de entrevista televisiva)

A atravessar cada uma destas categorias emerge o tema da "Equidade e igualdade", com $13,8 \%$ das codificações. As narrativas antecipam que os conteúdos e formas de avaliação devem prever as diferenças de acesso ao conhecimento e à interação com os docentes, mas, sobretudo, que os agentes devem preocupar-se em assegurar os recursos necessários à participação (principalmente, através de equipamentos e de serviços). Por exemplo:

Mas há razões para temer que, apesar dos apoios sociais já assegurados quer aos alunos dos ensinos básico e secundário quer aos estudantes do superior, esta pandemia venha a ter consequências negativas também no agravamento das desigualdades sociais e educativas às quais todos devemos estar atentos e contribuir para minorar. (Orgão consultivo, 25 de março, documento escrito, carta) 
Há, ainda assim, uma diferença, localizada nos papéis, que deve ser referida. Durante a primeira fase, vários representantes de professores, encarregados de educação e diretores consideram que seria pertinente a antecipação da interrupção letiva da Páscoa em quinze dias, para que as escolas pudessem preparar-se para a mudança para o espaço digital,

\begin{abstract}
Neste momento o mais fácil é antecipar as férias da páscoa, até por questões pedagógicas. As férias da páscoa estão aí a duas semanas e eventualmente será a medida que a todos facilitará a vida e os objetivos que nos propusemos no início do ano letivo. Para já julgo que seria uma medida que teria menos impactos nos objetivos pedagógicos e das escolas e famílias. (Representante dos Encarregados de Educação, 12 de março, entrevista a programa radiofónico)
\end{abstract}

com o estado português a adotar a posição de que essas semanas não são dispensáveis porque, principalmente, seria importante dar início ao ensino à distância (pôr a máquina em movimento):

Nós tínhamos três objetivos [...]. Um deles iniciar o processo [...], de certa forma o
arrancar o processo parece um objetivo vago e evidente, mas sabemos que um processo
com esta natureza complexa, única e simplesmente arrancar implicava romper uma
inércia enorme e foi possivel. (Estado, 14 de abril, entrevista a programa
radiofónico)

Quanto à mobilização dos agentes, os dados sugerem uma atividade intensa por parte dos representantes do estado (22,3\% das narrativas consideradas), das direções das escolas $(24 \%)$, dos sindicatos dos professores $(26,6 \%)$ e das confederações de encarregados de educação $(8,9 \%)$ em dirigirem-se à situação e traduzirem as visões daqueles que representam.

É relevante uma certa iniquidade da intervenção dos restantes agentes. A academia apresenta discursos assertivos e contribuiu com 12,8\% das narrativas consideradas, embora em espaços de opinião em jornal (portanto, não estratégicos) e os órgãos consultivos e os alunos têm uma representação minimalista (respetivamente 4\% e 1,4\%).

\title{
4.3. A avaliação externa das aprendizagens: Primazia da ordenação
}

Aqui, procuramos responder às perguntas: "Qual a posição que os agentes adotam acerca da AEA dos alunos?” e “Que argumentos são utilizados para justificar a posições adotadas?”. Os dados indicam que, desde a primeira fase, o estado e os representantes dos professores, diretores e encarregados de educação focam os seus discursos na função de certificação/progressão/ordenação (entre 61,2\% e 81,2\% das codificações por agente tabela 3) e, neles, manifestam a prevalência da AEA para efeitos de ordenação sobre todas as outras formas.

Tabela 3. Frequências relativas das codificações acerca do tema especifico AEA (funções)

\begin{tabular}{lcccccc}
\hline & Professores & ÓRGÃos & ESTADo & EE & DIRETORES & CIÊNCIA \\
\hline $\begin{array}{l}\text { Apoio ao ensino e } \\
\text { aprendizagem }\end{array}$ & $25,2 \%$ & $25 \%$ & $14,6 \%$ & $12,5 \%$ & $9,7 \%$ & $13,3 \%$ \\
\hline $\begin{array}{l}\text { Certificação, } \\
\text { progressão e } \\
\text { ordenação }\end{array}$ & $61,2 \%$ & $66,7 \%$ & $77 \%$ & $81,2 \%$ & $80,5 \%$ & $73,3 \%$ \\
\hline $\begin{array}{l}\text { Especificamente } \\
\text { ordenação }\end{array}$ & $(23,3 \%)$ & $(25 \%)$ & $(50 \%)$ & $(43,8 \%)$ & $(40,3 \%)$ & $(40 \%)$ \\
\hline $\begin{array}{l}\text { Pilotagem e } \\
\text { avaliação do } \\
\text { sistema }\end{array}$ & $13,6 \%$ & $8,3 \%$ & $8,3 \%$ & $6,3 \%$ & $9,7 \%$ & $13,4 \%$ \\
\hline Fonte: Elaboração própria. & & & & & \\
\hline
\end{tabular}

Fonte: Elaboração própria. 
Assim, aceitam, desde logo, que a retoma e reposição de aulas no ano letivo corrente ocorra com orientação para os alunos que realizarão os Exames Nacionais do Ensino Secundário e o cancelamento das provas de aferição e das provas finais do $9^{\circ}$ ano de escolaridade.

\begin{abstract}
Devem ser suspensas [...] as provas de aferição, dado não terem relevância, nem efeitos na progressão de ano ou conclusão de ciclo [...], a conclusão de ciclo dos alunos do $9^{\circ}$ ano deve ficar dependente, apenas, da avaliação sumativa interna [...] os exames nacionais [...] poderão ser reagendados para o mês de setembro, mesmo com ligeiro prejuízo da data de início do próximo ano escolar e dos prazos de candidatura ao ensino superior. (Órgão consultivo, 06 de abril, documento escrito, Comunicado)
\end{abstract}

Ao longo do tempo o estado conserva, no essencial, o seu posicionamento de que os exames para acesso ao ensino superior devem manter-se, caso existam condições de segurança. Já os encarregados de educação, professores e diretores têm uma representação menos linear. Vão, a espaços, rever a sua posição, para salientar que esses exames não são mais importantes que a saúde pública e sugerir que se torna necessário rever o processo de acesso ao ensino superior, mas projetam essa necessidade para o futuro, quando houver oportunidade de debate.

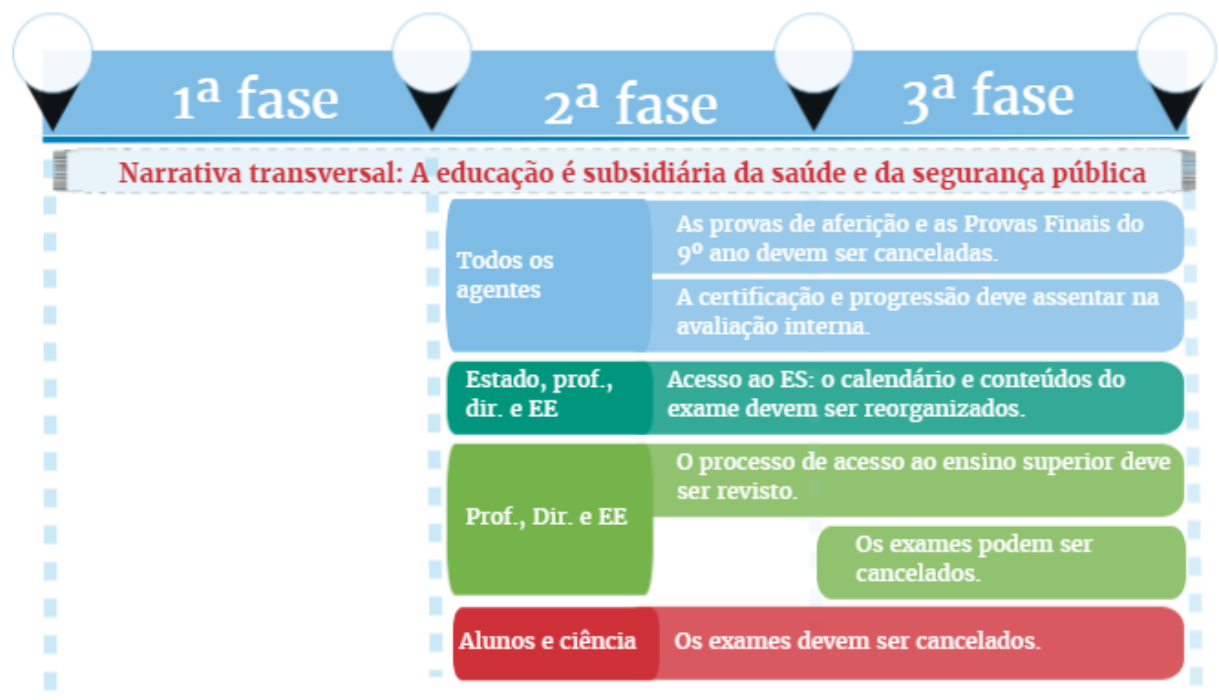

Figura 3. Narrativas específicas acerca da avaliação externa das aprendizagens Fonte: Elaboração própria.

Posição contrária é adotada pelos alunos e por vários membros da academia. Os alunos apelam ao cancelamento de todas as AEA, com os argumentos de que

Não estão asseguradas as condições minimas aceitáveis para uma avaliação deste género, tranquilidade, estabilidade, bem como a universalidade de acesso ao conhecimento na fase final do ano letivo. (Alunos, 15 de abril, documento escrito, Petição Pública)

Os membros da academia adotam o racional de que o sistema educativo português está excessivamente regulado pelas provas de exame e que esse excesso não pode justificar riscos para a saúde:

No que diz respeito à escola e ao ensino, julgo que esta pandemia trouxe ao de cima uma das fragilidades do sistema de ensino [...]: o ensino centrado nas avaliações $e$ em concreto nos exames (no secundário). Tudo acontece para e em função dos mesmos. As medidas que o Governo coloca em cima da mesa para resolver o problema do 
regresso às aulas fazem exatamente isso mesmo, focar nos exames e nos alunos que os vão fazer. (Academia, 19 de abril, artigo de opinião em jornal)

Entretanto, as intervenções dos agentes deixam perceber as suas representações acerca dos vários tipos de instrumentos de AEA.

Uma parte significativa das narrativas (20,7\%) adota um discurso indiferenciado, limitado a uma apreciação sobre a situação que cada tipo de AEA deve assumir devido à pandemia.

A função de apoio ao ensino e à aprendizagem (11,6\% das narrativas codificadas) é desvalorizada e prescindida e a função de certificação e progressão (22,6\% das codificações) recebe a narrativa de que é dispensável face à existência de processos contínuos de avaliação interna das aprendizagens. Por exemplo:

O próprio exame do $9^{\circ}$ ano, podemos perguntar [...] o exame do nono ano não é
eliminatório, o exame do $9^{\circ}$ ano não é determinante para coisa nenhuma, o exame do
nono ano é pouco mais do que uma prova de aferição tem uma ponderação muito curta
na própria avaliação dos alunos e, portanto, é algo que também não tem sentido.
(Representante dos professores, 27 de março, vídeo de entrevista televisiva)

A função de ordenação dos alunos é aquela que prevalece (42\% do total de todas as narrativas específicas acerca das provas de AEA) e as atividades que lhes estão na base são as únicas que justificam que os alunos retomem as atividades letivas - ainda que subordinado à existência de condições de saúde e segurança - e que o calendário escolar seja reorganizado para que estas provas possam ocorrer mais tarde, aceitando-se que o concurso de acesso ao ensino superior seja remetido para fim de setembro ou início de outubro. Por exemplo:

Relativamente aos exames, que é esta a grande preocupação dos encarregados de educação, uma classificação, uma ordenação de prioridades para depois entrar no ensino superior. Nós, há muito que vimos chamando a atenção que é preciso alterar isto, percebemos e temos confiança que neste momento não é fácil mudar o processo de acesso e de seleção, mas é possível acabar o $12^{\circ}$ com uma avaliação criteriosa, uma avaliação rigorosa feita pelas escolas e depois sim, os exames em julho ou em setembro. (Representante dos Encarregados de Educação, 13 de abril, entrevista a programa radiofónico)

Esta posição assenta em dois tipos de argumentos. No primeiro, o estado português e os representantes dos diretores falam através da sua interpretação das expectativas dos alunos - de que estes querem realizar os Exames Finais -, para defender que elas devem ser respeitadas e alegam, também, que o acesso ao ensino superior não teria equidade ou justiça se não fosse moderado por instrumentos externos.

O segundo, de naturalização e normalização das provas, nomeadamente que as escolas, o calendário, os próprios exames e a oferta de atividades letivas podem ser reconfigurados para que a AEA se realize. Em certa medida, os exames são olhados como uma inevitabilidade cuja ausência deixaria o percurso incompleto:

Seja qual for a decisão que o ministério venha a tomar, nenhum aluno deve ficar prejudicado, nem nas expectativas, nem de forma funcional. Se os alunos trabalham e trabalharam, se têm expectativas, em nenhuma circunstância podemos falhar essas expectativas, e que os objetivos não sejam atingidos por culpa que não seja a deles. $E$ claro que, se não houver outra solução, [...], a única solução para garantir a igualdade e a equidade é garantir que haja exames, quando tiver de ser, se tiver de ser em setembro ou em outubro que seja. (Representante de Diretores, 13 de abril, entrevista a programa radiofónico)

Não sabemos como poderemos retomar, mas queremos fechar o ensino secundário e fazer os exames para poder dar o salto e assegurar a vida daqueles que têm de ter 
alguma previsibilidade. Isso é algo que nos preocupa, salvaguardar os passos de vida $e$ os projetos dos nossos alunos. (Estado, 14 de abril, entrevista a programa radiofónico)

\section{Discussão}

A discussão está dirigida à vertente ética que esta investigação assume, de oferecer ponderação acerca das decisões tomadas. Para isso, mobiliza os dados, as medidas adotadas e o enquadramento de outras pesquisas, para debater quatro dissonâncias emergentes.

A primeira dissonância encontra-se nas diferenças entre a narrativa de que a saúde e segurança estão em primeiro lugar e a deslocalização dos alunos dos $11^{\circ}$ e $12^{\circ}$ ano desse primado, devido à AEA para ordenação de candidaturas ao ensino superior. Esta dissonância pode dever-se à crença de que o rigor e a justiça no acesso ao ensino superior apenas são conseguidos através de avaliações ex ternas. Contudo, sabemos que nem o rigor é perfeito, nem a aprendizagem é potenciada através dessas provas (Au, 2008; Fernandes, 2014, 2019; Madaus, Russell e Higgins, 2009). Surge à tona o argumento de que um único momento de avaliação está mais sensível ao problema da justiça, porque qualquer imparidade tem impactos enormes na ordenação, enquanto momentos contínuos de avaliação podem esbater esse problema.

O que aqui queremos salientar, é que esta dissonância sugere uma reconfiguração: os exames nacionais do ensino secundário têm sido considerados do tipo moderate stakes, (Fernandes, 2019) pelo critério do grau com que os resultados são usados na progressão académica dos alunos e na avaliação das escolas e dos professores, mas os dados atuais apontam que é preciso integrar o valor social entranhado das provas, neste caso que elas justificam a tomada de risco (aulas presenciais) e que o futuro dos jovens seja adiado e, nestes critérios, que os Exames Nacionais Finais são do tipo Very High Stakes.

A segunda dissonância encontra-se nas narrativas que consideram que avaliação interna merece a confiança dos agentes para efeitos de certificação, mas não para ordenação, sobretudo quando vários atores defendem que o acesso ao ensino superior deve ser revisto. Talvez a raiz desta dissonância esteja noutra crença acerca da qualidade do sistema educativo, a de que os resultados das avaliações internas e externas devem ser próximos.

Note-se, contudo, que o que as provas de AEA permitem avaliar, não abarca a totalidade do Perfil do Aluno que lhes serve de referência. Então, apesar da diversidade humana (Gardner, 1993; Kolb, 1984; Sternberg, 1997), os exames favorecem os alunos com orientação para o que pode, de facto, ser avaliado através deles. Nessa medida, os tempos de pandemia parecem ter desvelado (ou, talvez, consolidado) que o perfil do aluno à saída da escolaridade obrigatória, não corresponde ao perfil do aluno à entrada do ensino superior, e aponta um espaço vitalício de erro educativo: se o tempo de ensino está orientado para a integridade do Perfil, poderá limitar o acesso (talvez o sucesso) ao ensino superior; se é focado nas competências com valor externo, a formação plena do cidadão poderá falhar.

Talvez se deva questionar porque é que instrumentos focados em aprendizagens diferentes estão, em algumas escolas, na origem de classificações semelhantes? Pensamos que esta pressão para a igualdade é pouco conhecida, apesar de poder estar a influenciar as decisões políticas e merece ser alvo de investigações futuras. 
A terceira dissonância emerge do diálogo entre a equidade e as medidas adotadas. Por um lado, os discursos mostram a preocupação transversal para com a igualdade de oportunidades e a equidade social; por outro, alguns agentes tomam ou apoiam medidas que têm grande sensibilidade social e efeitos negativos na equidade.

Desde logo, os agentes (com exceção dos alunos e da academia) promovem a manutenção de provas de AEA com mais potencial de iniquidade (Bray, 2007; Harlen, 2003; Salmi e Bassett, 2014), a que se junta a situação específica da aprendizagem remota: os agentes assumem a consciência de que nem todos os alunos poderão aprender nas mesmas condições e a ciência tem evidenciado que o ensino à distância pode afetar negativamente os alunos com menor aproveitamento académico e provenientes de contextos minoritários ou deprimidos (Bettinger et al., 2017). Além disso, o Estado acrescenta um espaço de liberdade familiar, a decisão de permitir que os estudantes frequentem as aulas presenciais, o que força a pesar entre a proteção da saúde ou a recuperação das aprendizagens. As opções diferenciadas das famílias, significam que alguns alunos terão menos acesso às oportunidades de aprendizagem devido a fatores fora do seu controlo.

Então, se as sociedades justas e equitativas são aquelas em que as interações entre os seus membros, para além de livres e iguais, permitem condições de tirar proveito das oportunidades (Nussbaum, 2011; Rawls, 1985, 2013; Sen, 1985), os dados apontam que a ação dos atores decisórios se socorreu de crenças incompletas, de que a justiça é cumprida apenas pela satisfação da condição de igualdade.

Talvez este desiquilibrio resida na orientação para os resultados que a educação tem adotado (Grek, 2009; Lingard, Martino e Rezai-Rashti, 2013; Maroy e Voisin, 2013), já que é politicamente mais fácil medir a igualdade (Flores, 2017) (todos realizam a mesma prova), do que assumir uma orientação para o cuidado (Gilligan, 1993, 2013), que coloca as necessidades e diferenças das crianças e jovens no centro da decisão.

Nessa medida, esta dissonância sugere que o foco do debate vindouro deverá ser a visão incompleta da justiça na educação (as causas) e não a necessidade de digitalizar o ensino ou de rever o concurso de acesso ao ensino superior (os sintomas). Caso não o façamos poderemos estar, meramente, a prolongar o problema essencial.

Há uma última dissonância que emerge e que aqui queremos apontar, apesar de se encontrar à margem das questões de investigação. Afinal, as Ciências da Educação movem-se na complexidade de ambientes educativos sujeitos a surpreender (Amado, 2011; Gonçalves, 2013) e a realidade que se estuda também deve ser conhecida pela admiração que promove (Feyerabend, 2010). Neste caso, há algo a debater acerca do sistema educativo.

A quarta dissonância encontra-se na mudança imediata do ensino para o espaço virtual, apesar de vários agentes sugerirem que deveria ter acontecido uma pausa que permitisse reflexão e preparação.

Por deliberação política colocou-se, repentinamente, os nativos do mundo digital em interação com aqueles que para aí imigraram (Prensky, 2001), apesar de sabermos que o processo de ensino através de canais digitais sugere um currículo situacional para preparar os alunos para aprender numa nova realidade e não dispensa a formação dos professores (Mayer, 2020; Senjov-Makohon, 2014) e processos próprios. 
$\mathrm{E}$ as intervenções dos agentes evidenciam que essa migração veloz teve impactos negativos que eram previsíveis (muito semelhantes aos que ocorreram em Hong-Kong, em 2002, durante a epidemia de SARS) (Fox, 2004).

Uma explicação possível para a mudança radical pode encontrar-se numa visão de proletarização do professor (Pavan e Backes, 2016), em que os docentes vão, gradualmente, perdendo a sua autonomia para agir, planear e até refletir no contex to das suas realidades e o processo de ensino é do tipo prêt-à-porter. Portugal esteve recentemente sujeito a constrangimentos em virtude da crise económica de 2009-2015, em que foram implementados métodos de controlo através dos resultados das AEA, o que homogeneizou as escolas e retraiu a sua capacidade de reflexão.

Fazemos notar que a velocidade e centralidade das medidas e uma intervenção em particular parecem remanescer desta vertigem de proletarização: o estado clarificou que, no cancelamento das atividades presenciais, "[...] os professores não estão de férias" (13 de março, artigo de jornal), o que pode sugerir que a reflexão docente não é dos trabalhos valorizados (sobre a sua importância, ver, por exemplo, Bernal, Pérez e Jiménez, 2007; Gess-Newsome, 2015, Shulman, 1986).

Portanto, parece que o sistema educativo soube flexibilizar-se para, na essência, manter a sua estrutura (os conteúdos, a ordenação, as etapas do calendário); mas que não foi capaz de se adaptar. A adaptabilidade sugere outro tipo de interação, uma em que as escolas possam modificar-se para algo que emerge da situação e das interações únicas que apenas poderiam ser experimentadas neste tempo excecional (Cilliers, 1998; Fullan, 2001; Hamido, 2007; Silva, 2019). Talvez este período faça merecer um debate mais aprimorado sobre a forma como, em Portugal, organizamos a educação: flexibilidade ou adaptabilidade?

\section{Conclusão}

Os resultados que obtivemos, assim como a discussão e estas conclusões, devem ser lidos no contexto de incerteza em que têm as suas raízes e na consciência de que todas as metodologias têm caraterísticas que influenciam a interpretação. Por um lado, os documentos analisados não foram produzidos para alimentar, especificamente, a investigação; por outro, alguns argumentos que suportaram as decisões políticas podem ter sido mantidos reservados; e, as perceções de agentes com menos espaços públicos poderão estar mal representados.

Contudo, este momento de pandemia oferece uma janela privilegiada (talvez mais genuína) para algumas representações que podem estar a influenciar o sistema educativo português e, portanto, contribui para que o compreendamos. Em particular, aponta quatro dissonâncias que se transformam em quatro desafios para os agentes, o sistema e a investigação.

Os resultados sugerem o entranhamento de padrões de que as AEA são a garantia de rigor, da equidade e da justiça e que o dia-a-dia da aprendizagem tem validade dentro das escolas, mas não possui validade externa, de certa forma, as AEA para ordenação dos alunos traduzem uma mundividência que permite falta de coerência entre as necessidades dos agentes, as medidas e os dados científicos. Poderiam ter sido tomadas outras decisões: 
- Para adiantar, em vez de adiar, a vida dos alunos. O acesso ao ensino superior traduz algum grau de controlo sobre la vida e é uma tarefa que os jovens devem cumprir antes da entrada numa profissão (Lamb e Bornstein, 2011) e a aprendizagem é facilitada quando parte desse controlo está com os alunos (Deci e Ryan, 2000; Deci, Koestner e Ryan, 1999). A decisão de adiar o calendário de acesso ao ensino superior (para datas condicionadas) e de manter as AEA para esse efeito, parece retirar dos alunos o pouco controlo que têm da situação, aumentar as incertezas e impedir o fecho de uma etapa;

- De prever uma avaliação formativa da situação para tão breve quanto possível, agendando-se provas de aferição para o primeiro momento seguro, o que possibilitaria o remedeio informado dos efeitos negativos da pandemia;

- De permitir uma das tarefas nobres dos agentes educativos, a de refletir sobre os seus cursos de ação (antecipando, como foi sugerido por vários agentes, a interrupção letiva da Páscoa). A realidade em que vivemos foi construída através do pensamento e é nele que se encontram as ferramentas para a reversão de erros, a regeneração societária e a humanização (Morin, 2005).

Naturalmente, nenhuma decisão está liberta de efeitos imprevistos. Nessa medida, os caminhos diferentes que aqui apontamos são usados para privilegiar, precisamente, a conceção de que a ação, em tempos e ambientes imprevisíveis, não pode recorrer aos mesmos mecanismos de linearidade usados quando há ordem e certezas (Silva, 2019). A complexidade clama por coerência em vez de exatidão, porque a coerência permite soluções diferenciadas em cada contexto (Silva, 2019; Snowden e Boone, 2007), enquanto a exatidão aceita soluções iguais, ainda que, como neste caso, dissonantes. E para sugerir que as Ciências da Educação - aparentemente tão afastadas das narrativas -, podendo ter atuado em domínios mais privados, também devem esforçar-se por preencher os espaços públicos, onde se constroem perceções que, inevitavelmente, influenciam as escolas, a educação e a aprendizagem.

\section{Referências}

Afonso, A. N. (2009). Nem tudo o que conta em educação é mensurável ou comparável. Crítica à accountability baseada em testes estandardizados e rankings escolares. Revista Lusófona de Educação, 13, 13-29.

Afonso, N. e Costa, E. (2014). Knowledge moves: Transition and fluidity in the policy process. Em R. Freeman e S. Sturdy (Orgs.), Knowledge in policy: Embodied, inscribed, enacted. Studies of health and education in Europe (pp. 57-82). Policy Press. https://doi.org/10.1332/policypress/9781447309987.003.0003

Amado, J. (2011). Ciências da educação: Que estatuto epistemológico? Revista Portuguesa de Pedagogia, 12(2), 45-55. https://doi.org/10.14195/1647-8614_Extra-2011_4

Au, W. W. (2008). Devising inequality: A bernsteinian analysis of high-stakes testing and social reproduction in education. British Journal of Sociology of Education, 29(6), 639-651. https://doi.org/10.1080/01425690802423312

Baker, M. e Johnston, P. (2010). The impact of socioeconomic status on high stakes testing reexamined. Journal of Instructional Psychology, 37(3), 193-199. 
Bernal, B. V., Pérez, R. J. e Jiménez, V. M. (2007). El desarrollo profesional del profesorado de ciencias como integración y práctica. La hipóteses de la complejidad. Revista Eureka, 4(3), 372-393. https://doi.org/10.25267/Rev_Eureka_ensen_divulg_cienc.2007.v4.i3.01

Best, M., Knight, P., Lietz, P., Lockwood, C., Nugroho, D. e Tobin, M. (2013). The impact of national and international assessment programmes on education policy, particularly policies regarding resource allocation and teaching and learning practices in developing counties. EPPI.

Bettinger, E. P., Fox, L., Loeb, S. e Taylor, E. (2017). Virtual classrooms: How online college courses affect student success? American Economic Review, 107(9), 2855-2875. https://doi.org/10.1257/aer.20151193

Black, P. e Wiliam, D. (2010). Inside the black box: Raising standards through classroom. Phi Delta Kappan, 92(1), 81-90. https://doi.org/10.1177/003172171009200119

Bray, M. (2007). The shadow education system: Private tutoring and its implications for planners. UNESCO.

Carmo, H. e Ferreira, M. (2015). Metodologia da investigação: Guia para a autoaprendizagem. Universidade Aberta.

Carvalho, L. M., Costa, E. e Sant'Ovaia, C. (2020). Depicting the faces of results-oriented regulatory processes in Portugal: National testing in policy texts. European Educational Research Journal, 19(2), 125-141. https://doi.org/10.1177/1474904119858799

Cho, E. Y. e Chan, T. M. (2020). Children's wellbeing in a high-stakes testing environment: The case of Hong Kong. Children and Touth Services Review, 109, 1-11. https://doi.org/10.1016/j.childyouth.2019.104694

Cilliers, P. (1998). Complexity and Postmodernism. Understanding complex systems. Routlegde.

Cilliers, P. (2000). What can we learn from a theory of complexity? Emergence, Complexity and Organization, 2(1), 23-33. https://doi.org/10.1207/S15327000EM0201_03

Conselho da União Europeia. (2018). Recomendação 2018/C 189/O1 - Sobre as competências essenciais para a aprendizagem ao longo da vida. Conselho da União Europeia

Conselho Nacional de Educação. (2015). Avaliação externa das escolas. Conselho Nacional de Educação.

Coutinho, C. (2011). Metodologia da investigação em ciências sociais e humanas: Teoria e prática. Almedina.

Creswell, J. W. (2012). Educatinal research: Planning, conducting, and evaluating quantitative and qualitative research. Pearson Education Inc.

Crocker, L. (2004). Teaching for the test: How and why test preparation is appropriate. En R. P. Phelps (Ed.), Defending standardized testing (pp. 159-174). Lawrence Erlbaum Associates.

Deci, E. L. e Ryan, R. M. (2000). The "what" and "why" of goal pursuits: Human needs and the self-determination of behavior. Psychological Inquiry, 11, 227-268.

https://doi.org/10.1207/S15327965PLI1104_01

Deci, E. L., Koestner, R. e Ryan, R. M. (1999). A meta-analytic review of experiments examining the effects of extrinsic rewards on intrinsic motivation. Psychological Bulletin, 125, 627-668. https://doi.org/10.1037/0033-2909.125.6.627

Eurydice. (2009). Les évaluations standardisées des élèves en Europe: Objectifs, organisation et utilisation des résultats. Eurydice. 
Fernandes, D. (2014). Avaliações externas e melhoria das aprendizagens dos alunos: Questões críticas de um arelação (im)possível. En Conselho Nacional de Educação (Ed.), Avaliação externa e qualidade das aprendizagens (pp. 21-49). Conselho Nacional de Educação.

Fernandes, D. (2019). Avaliações externas e aprendizagens dos alunos: Uma reflexão crítica. Linhas Críticas, 25, 644-660. https://doi.org/10.26512/lc.v25io.24579

Feyerabend, P. K. (2010). Against method. Verso Books.

Flores, G. C. (2017). Igualdad y equidad en educación: Tensiones y transiciones. Educación, 26(51), 159-174. https://doi.org/10.18800/educacion.201702.009

Fox, R. (2004). SARS epidemic: Teachers' experiences using ICTs. En R. Atkinson, C. McBeath, D. Jonas-Dwyer e R. Phillips (Eds.), Beyond the comfort zone. Proceedings of the 21st ASCILITE Conference (pp. 319-327). ASCILITE

Fullan, M. (2001). Leading in a culture of change. Jossey-Bass.

Fullan, M. (2009). Large-scale reform comes of age. Journal of Educational Change, 10, 101-113. https://doi.org/10.1007/s 10833-009-9108-Z

Gardner, H. (1993). Inteligencias múltiples. Paidós.

Gess-Newsome, J. (2015). A model of teacher professional knowledge and skill including PCK: Results of the thinking from the PCK Summit. En A. Berry, A. Frieddrichsen e J. Loughran (Eds.), Reexamining pedagogical content knowledge in science education (pp. 28-42). Reutledge.

Gilligan, C. (1993). In a different voice: Psychological theory and women's development. Harvard University Press.

Gilligan, C. (2013). La ética del cuidado. Fundación Víctor Grífols i Lucas.

Gonçalves, T. (2013). Ciências da educação e ciências cognitivas: Contributos para uma abordagem transdisciplinar. Revista Portuguesa de Educação, 25(1), 217-239. https://doi.org/10.21814/rpe.3022

Grek, S. (2009). Governing by numbers: The PISA effect in Europe. Journal of Education Policy, 24(1), 23-37. https://doi.org/10.1080/02680930802412669

Hamido, G. (2007). Escola, ecologia viva e reflexiva: O poder de mudar. Interacções, 7, 141-178. https://doi.org/10.25755/int.349

Harlen, W. (2003). The inequitable impacts of high stakes testing. Education Review, 17(1), 43-50.

Hatch, J. A. (2002). Doing qualitative research in education settings. State University of New York.

Inspeção-Geral da Educação e da Ciência. (2020). Avaliação externa das escolas: Referentes $e$ instrumentos de trabalho. Inspeção-Geral da Educação e da Ciência.

Johnson, E. G. (1992). The design of the national assessment of educational progress. Journal of Educational Measurement, 29(2), 95-110. https://www.jstor.org/stable/1434597

Jones, B. D. (2007). The unintended outcomes of high-stakes testing. Journal of Applied School Psychology, 23(2), 65-86. https://doi.org/10.1300/J370v23no2_05

Kolb, D. A. (1984). Experiential learning: Experience as the source of learning and development. Pratice Hall.

Lamb, M. E. e Bornstein, M. H. (2011). Social and personality development. An advanced textbook. Psychological Press. 
Lingard, B., Martino, W. e Rezai-Rashti, G. (2013). Testing regimes, accountabilities and education policy: Commensurate global and national developments. Journal of Education Policy, 28(5), 539-556. https://doi.org/10.1080/02680939.2013.820042

Madaus, G. F., Russell, M. K. e Higgins, J. (2009). The paradoxes of high stakes testing: How they affect students, their parents, teachers, principals, schools, and society. IAP.

Maroy, C. e Voisin, A. (2013). As transformações recentes das políticas de accountability na educação: desafios e incidências das ferramentas de ação pública. Educação E̊ Sociedade, 34(124), 881-901. https://doi.org/10.1590/So101-73302013000300012.

Mayer, R. E. (2020). Where is the learning in mobile technologies for learning. Contemporary Educational Psychology, 60, 18-24. https://doi.org/10.1016/j.cedpsych.2019.101824

Merriam, S. B. e Tisdell, E. J. (2016). Qualitative research: A guide to design and implementation. JosseyBass.

Moreira, J. A., Henriques, S. e Barros, D. (2020). Transitando de um ensino remoto emergencial para uma educação digital em rede, em tempos de pandemia. Dialogia, 34, 351364https://doi.org/10.5585/Dialogia.N34.17123

Morin, E. (1999). Seven complex lessons in education for the future. UNESCO.

Morin, E. (2005). O método VI: A ética. Publicações Europa-América.

Nussbaum, M. C. (2011). Creating capabilities: The human development approach. The Belknap. https://doi.org/10.4159/harvard.9780674061200

Ozga, J. e Grek, S. (2012). Governing through learning. School self-evaluation as a knowledgebased regulatory tool. Recherches Sociologiques et Anthropologiques, 43(2), 35-52. https://doi.org/10.4000/rsa.786

Pavan, R. e Backles, J. (2016). O processo de (des)proletarização do professor da educação básica. Revista Portuguesa de Educação, 29(2), 35-58. https://doi.org/10.21814/rpe.5957

Peräkylä, A. (2005). Analyzing talk and text. En N. K. Denzin e Y. S. Lincoln (Eds.), The SAGE handbook of qualitative research (pp. 869-886). SAGE.

Pinto, J., Costa, J. A. e Silva, J. C. (2014). Explicações, escolas e sucesso educativo: Reflexão em torno da educação sombra. Indagatio Didactica, 6(4), 25-36. https://doi.org/10.34624/id.v6i4.3905

Prensky, M. (2001). Digital natives, digital immigrants part 1. On the Horizon, 9, 1-6. https://doi.org/10.1108/10748120110424816

Rawls, J. (1985). Justice as fairness: Political not metaphysical. Philosophy \& Public Affairs, 3, 223251.

Rawls, J. (2013). Uma teoria da justiça. Editorial Presença.

Salmi, J. e Bassett, R. M. (2014). The equity imperative in tertiary education: Promoting fairness and efficiency. International Review of Education, 60, 362-377.

https://doi.org/10.1007/s11159-013-9391-Z

Sen, A. (1985). Commodities and capabilities. Elsevier. Oxford: Elsevier.

Senjov-Makohon, N. (2014). Cultural tools to enhance learning. European Scientific Journal, Special Edition, 1O(10), 204-210. https://doi.org/10.19044/esj.2014.v10n10p\%p

Shapiro, J. P. e Stefkovich, J. A. (2005). Ethical leadership and decision making in education: Applying theoretical perspectives to complex dilemmas. Erlbaum Associates Inc. 
Shulman, L. (1986). Those who understand: Knowledge growth in teaching. Educational Researcher, 15(2), 4-14. https://doi.org/10.2307/1175860

Silva, N. M. (2019). Liderar organizações complexas: O caso das escolas. Chiado Books.

Smith, W. C. (2014). The global transformation toward testing for accountability. Education Policy Analysis Archives, 22(116), 1-34. https://doi.org/10.14507/epaa.v22.1571.

Snowden, D. e Boone, M. E. (2007). A leader`s framewok for decision making. Harvard Business Revier, 149, 68-76.

Sousa-Pereira, F. e Leite, C. (2019). Política do perfil dos alunos à saída da escolaridade obrigatória e desafios para a formação de professores. Revista de Educação, Ciência e Cultura, 24(1), 113122. https://doi.org/10.18316/recc.v24i1.5086

Stake, R. E. (2009). A arte da investigação com estudos de caso. Fundação Calouste Gulbenkian.

Sternberg, R. (1997). Successful intelligence. Penguin Putnam.

\section{Agradecimentos}

Na nossa experiência, raramente há autoria sem mentoria. Queremos agradecer a disponibilidade da Dr. ${ }^{a}$ Isabel Fialho e do Dr. Paulo Costa, do Centro de Estudos em Educação e Psicologia da Universidade de Évora e os comentários dos avaliadores externos.

\section{Breve CV dos autores}

\section{Nuno Miranda}

É licenciado em Ciências do Desporto, pela Universidade Técnica de Lisboa, Mestre em Gestão e Administração Educacional, Pela Universidade Aberta e investigador de Doutoramento em Ciências da Educação, junto do Centro de Investigação em Educação e Psicologia da Universidade de Évora. Tem desenvolvido investigação nas áreas das políticas educativas e liderança educacional à luz da Teoria da Complexidade e projetos e pesquisas na área do desporto e da sua relação com a inclusão social. É professor do Ensino Básico e Secundário no Agrupamento de Escolas de Montemor-o-Novo, e formador de professores. ORCID ID: https://orcid.org/OOOO-O002-3574-7679. E-mail: nunosilva@aemn.pt

\section{Sónia Pereira}

É licenciada em Psicologia e Mestre em Psicologia na Área da Educação, pela Universidade de Évora e investigadora de Doutoramento em Ciências da Educação, junto do Centro de Investigação em Educação e Psicologia da Universidade de Évora. É professora no Ensino Superior Angolano, em cursos nas áreas da Psicologia e da Educação e tem desempenhado cargos de gestão e liderança em instituições de ensino superior do país. Presentemente, desenvolve investigação na área do desenvolvimento profissional dos professores e das aprendizagens significativas. ORCID ID: https://orcid.org/oOOO-00024492-0322. E-mail: soniapsidinis@hotmail.com 